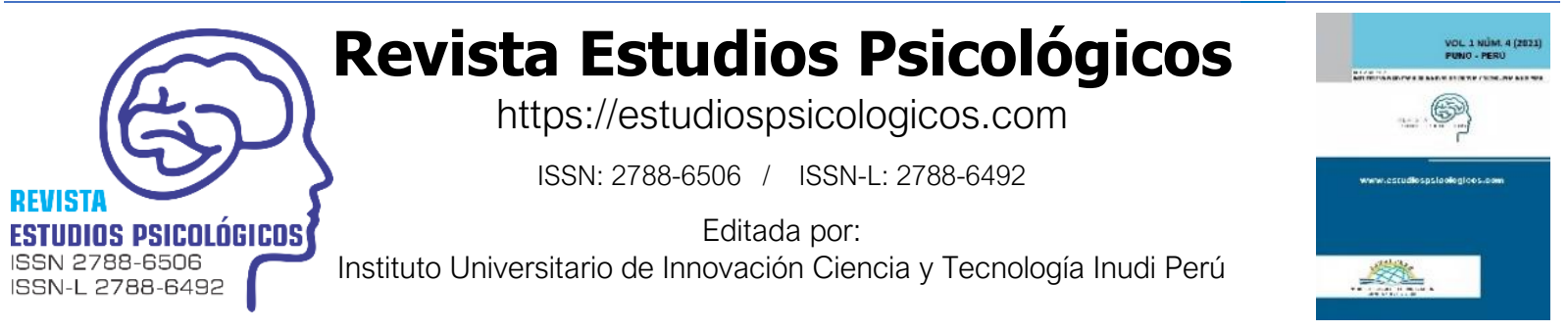

ARTÍCULO ORIGINAL

\title{
Efectos del síndrome post COVID-19 en la salud mental en niños y adolescentes
}

\author{
Effects of the post-COVID-19 syndrome on mental health in children and adolescents
}

Efeitos da síndrome pós-COVID-19 na saúde mental de crianças e adolescentes

\author{
Victor Guzmán-Brand ${ }^{1}$ \\ Corporación Unificada Nacional de Educación Superior, Bogotá D.C. - Cundinamarca, Colombia \\ (iD) https://orcid.org/0000-0002-6051-3153
}

D0l: https://doi.org/10.35622/j.rep.2022.02.001

Enviado: 23/11/2021/ Aceptado: 28/02/2022

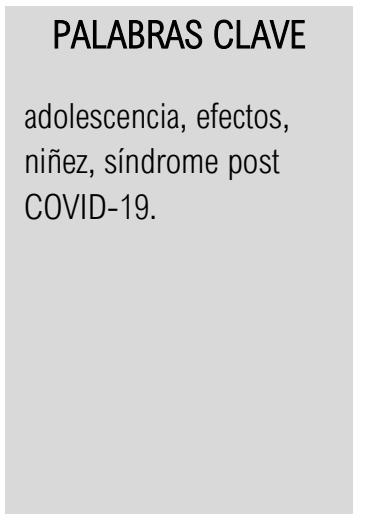

KEYWORDS

adolescence, effects, childhood, post COVID19 syndrome.
RESUMEN. Un gran porcentaje de las personas que han sido infectadas por el virus SARS CoV-2 causante de la conocida pandemia del COVID-19 y sus variantes, manifiestan que han tenido una prolongación por más de 12 semanas de síntomas relacionados con la enfermedad. Los niños, niñas y adolescentes no son ajenos a esta situación siendo una población vulnerable a los efectos prolongados del virus. Este estudio tiene como objetivo realizar una investigación descriptiva sobre los efectos del síndrome post COVID-19 en la niñez y adolescencia en las instituciones educativas de la localidad de la Candelaria. Para esto se realiza una investigación documental de artículos científicos sobresalientes sobre el estudio del síndrome post COVID-19 en la niñez y adolescencia. Se aplicó de una encuesta que agrupe los datos de los menores que han padecido la enfermedad después de 12 semanas. Las investigaciones sobre el tema apuntan a que la enfermedad del síndrome post COVID-19 en niños y niñas tiene un bajo riesgo, pero en adolescentes y adultos jóvenes se incrementa la posibilidad de padecer la prolongación de signos y síntomas del virus.

\footnotetext{
ABSTRACT. A large percentage of people who have been infected by the SARS CoV-2 virus that causes the known COVID-19 pandemic and its variants demonstrate that they have had a duration of more than 12 weeks with symptoms related to the illness. Children, girls, and adolescents cannot cope with this situation, being a population vulnerable to the prolonged effects of the virus. This study aims to carry out a descriptive investigation of the impacts of the post-COVID-19 syndrome on children and adolescents in the educational institutions of the locality of La Candelaria. For this, a documentary investigation of outstanding scientific articles on the study of the post-COVID-19 syndrome in childhood and adolescence is carried out. A survey was applied that grouped the data of the minors who had suffered the illness after 12 weeks. The investigations on the topic point out that the disease of the syndrome post-COVID-19 in children has low risk, but in adolescents and young adults, the possibility of suffering the prolongation of signs and symptoms of the virus increases.
}

\footnotetext{
${ }^{1}$ Correspondencia: victora.guzman@cun.edu.co
} 
PALAVRAS-CHAVE

adolescência, efeitos, infância, síndrome pósCOVID-19.
RESUM0. Uma grande porcentagem de pessoas que foram infectadas pelo vírus SARS CoV-2, que causa a conhecida pandemia de COVID-19 e suas variantes, afirma ter tido um prolongamento dos sintomas relacionados à doença por mais de 12 semanas. Crianças e adolescentes não são estranhos a essa situação, sendo uma população vulnerável aos efeitos prolongados do vírus. 0 objetivo deste estudo é realizar uma investigação descritiva sobre os efeitos da síndrome pósCOVID-19 na infância e adolescência em instituições educacionais da cidade de La Candelaria. Para isso, é realizada uma pesquisa documental de artigos científicos de destaque sobre o estudo da síndrome pós-COVID-19 na infância e adolescência. Foi aplicada uma pesquisa que agrupa os dados de menores que sofreram com a doença após 12 semanas. Pesquisas sobre 0 assunto indicam que a doença pós-síndrome da COVID-19 em meninos e meninas tem baixo risco, mas em adolescentes e adultos jovens aumenta a possibilidade de sofrer com o prolongamento dos sinais e sintomas do vírus.

\section{INTRODUCCIÓN}

Una de las preocupaciones latentes que ha trascendido con el paso de los días y con el arremeter de la pandemia del COVID-19 y sus variantes en el mundo, son los signos o síntomas prolongados del virus que se han diagnosticado en pacientes que han sido infectados, por esfuerzo personal y médico han superado la enfermedad en su estado más agresivo. Según el Instituto Nacional para la Excelencia en la Salud y la Atención (NICE 2020) los efectos a largo plazo de COVID-19 son "los signos y síntomas que se desarrollan durante 0 después de una infección compatible con COVID-19, continúan durante más de 12 semanas y son no explicado por un diagnóstico alternativo" (p.2). De igual forma, la Organización Mundial de la Salud (2020) realiza la definición de este síndrome cuando es manifestado en "personas con antecedentes de infección probable 0 confirmada por el SARS CoV-2, generalmente 3 meses desde el inicio del COVID-19 con síntomas y que duran al menos 2 meses y no pueden explicarse con un diagnóstico alternativo" (p.5).

El Centro de Control y Prevención de Enfermedades de Estados Unidos (CDC) expone que las personas que han sido contagiadas con el SARS-CoV-2 el virus que produce el COVID-19 poseen síntomas clínicos frecuentes o contantes en un tiempo de cuatro o más semanas después de contraer la enfermedad, ocasionalmente después de la recuperación. Estas molestias continuas pueden presentarse en personas que han padecido diferentes grados de la afección a lo largo de la infección aguda, por otro lado, los pacientes que manifestaron síntomas leves 0 asintomáticos también pueden llegar a padecer de estas condiciones o prolongación de los signos de la enfermedad. Es así como, las implicaciones a la salud del este síndrome post COVID-19 está en proceso de investigación.

Grafica 3. Definición del Síndrome Post COVID-19.

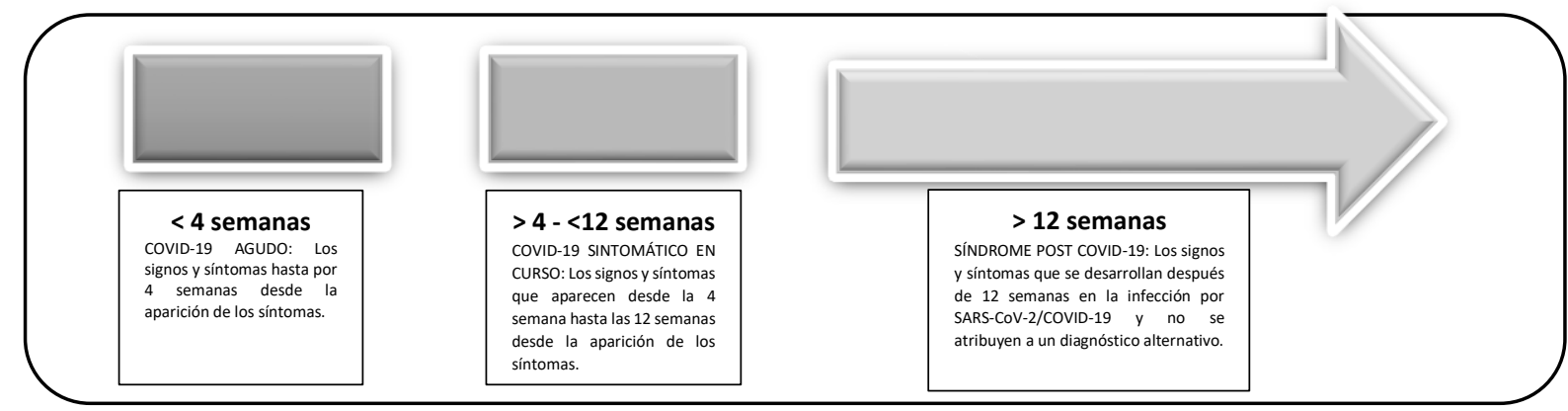

Nota: Tomado en base al Suplemento 1 Consenso Colombiano SARS-CoV-2/COVID-19. Asociación Colombiana de infectología. Síndrome Post COVID-19: complicaciones tardías y rehabilitación. (2021). Creación propia. 
Los estudios demuestran que los niños, niñas y adolescentes tienen una gran posibilidad de ser asintomáticos o que la enfermedad progrese de forma leve y transitoria seguidamente de la infección por el virus SARS-CoV2, en relación con la población adulta que tiene mayor riesgo de padecer niveles graves de la enfermedad, sin embargo, los niños, niñas y adolescentes aunque tienen una recuperación más rápida, algunos pueden padecer de síntomas prolongados que perseveran durante muchas semanas después de la infección con el virus (Behnood et al., 2022).

En constante, se tiene un repunte de casos del síndrome hiperinflamatorio de forma tardía en menores recuperados de la infección, condición de mayor observación en los Estados Unidos con 186 casos de pacientes con MIS-C (Giraldo et al., 2020). La Organización Mundial de la Salud (2020) expone en un estudio de la situación en 345 niños comprueba que el 23\% manifestaba una afección subyacente entre las que se encuentran neumopatías crónicas, enfermedades cardiovasculares e inmunodepresión.

El objetivo de la investigación es conocer las características del síndrome post COVID-19 en la salud mental en los niños, niñas y adolescentes, por lo tanto, se propone analizar el tema en relación con una búsqueda bibliográfica y aplicación de una encuesta online.

\section{MÉTODO}

Esta investigación se fundamentó en primer lugar en una revisión documental la cual tiene su sustento en la búsqueda, análisis e interpretación de datos primarios de información, como libros y artículos científicos registrados en fuentes electrónicas (Arias, 2006). Se examinaron las bases de datos como Pubmed, ScienceDirect y Google académico, artículos científicos publicados en los años 2020 al 2021. Se utilizó términos como síndrome post COVID, long COVID, COVID prolongado, además de su incidencia en la salud de los niños, niñas y adolescentes.

De igual manera se clasificaron los artículos de acuerdo con la información relevante sobre los efectos prolongados en niños, niñas y adolescentes, especialmente en aquellos que tuvieran relación con los síntomas psiquiátricos, psicológico y de salud mental vinculados a la prevalencia de la enfermedad, estos escritos en inglés o español. Luego se efectuó un estudio minucioso de su contenido, marcando la información relevante y los resúmenes correspondientes, de este trabajo se hallaron 60 artículos de los cuales sobresalieron 16 al tener una relación con el tema en estudio, sin embargo, solo 11 de estos contienen información específica sobre estudios del síndrome en niños, niñas o adolescentes.

Luego, se realizó una investigación de tipo descriptiva la cual pretende especificar las características del fenómeno (Hernández et al., 2014). Siendo las afecciones posteriores al COVID que son más frecuentes entre los pacientes recuperados, según la guía de identificación, evaluación y manejo de los efectos a largo plazo de COVID-19 desarrollada conjuntamente por NICE, Scottish Intercollegiate Guidelines Network (SIGN) y el Royal College of General Practitioners (RCGP) expuestas asi: 
Tabla 1

Signos y síntomas del síndrome post COVID-19

\begin{tabular}{|c|c|}
\hline Sistema & Síntomas \\
\hline Respiratorio & $\begin{array}{ll}\text { - } & \text { Falta de aliento } \\
\text { - } & \text { Tos }\end{array}$ \\
\hline Cardiovascular & $\begin{array}{ll}\text { - } & \text { Opresión en el pecho } \\
\text { - } & \text { Dolor en el pecho } \\
\text { - } & \text { Palpitaciones }\end{array}$ \\
\hline Generalizado & $\begin{array}{ll}\text { - } & \text { Fatiga } \\
\text { - } & \text { Fiebre } \\
\text { - } & \text { Dolor }\end{array}$ \\
\hline Neurologico & $\begin{array}{ll}\text { - } & \text { Deterioro cognitivo (niebla mental, perdida de concentración } 0 \\
\text { - } & \text { Droblemas de memoria) } \\
\text { - } & \text { Alteración del sueño } \\
\text { - } & \text { Síntomas de neuropatía periférica (hormigueo y entumecimiento) } \\
\text { - } & \text { Mareos } \\
\text { - } & \text { Delirio (en poblaciones mayores) } \\
\text { - } & \text { Impedimento de movilidad } \\
\text { - } & \text { Disturbio visual }\end{array}$ \\
\hline Gastrointestinal & $\begin{array}{ll}\text { - } & \text { Dolor abdominal } \\
\text { - } & \text { Náuseas y vómitos } \\
\text { - } & \text { Diarrea } \\
\text { - } & \text { Pérdida de peso y apetito reducido }\end{array}$ \\
\hline Musculoesqueletico & $\begin{array}{ll}\text { - } & \text { Dolor en las articulaciones } \\
\text { - } & \text { Dolor muscular }\end{array}$ \\
\hline Oido, nariz y garganta & $\begin{array}{ll}\text { - } & \text { Tinnitis } \\
\text { - } & \text { Dolor de oídos } \\
\text { - } & \text { Dolor de garganta } \\
\text { - } & \text { Mareos } \\
\text { - } & \text { Perdida del gusto y /o el olfato } \\
\text { - } & \text { Congestión nasal }\end{array}$ \\
\hline Dermatologico & $\begin{array}{ll}\text { - } & \text { Erupciones en la piel } \\
\text { - } & \text { Pérdida de cabello }\end{array}$ \\
\hline Psicologico/psiquiatrico & $\begin{array}{ll}\text { - } & \text { Depresión } \\
\text { - } & \text { Ansiedad } \\
\text { - } & \text { Trastorno de estrés postraumático }\end{array}$ \\
\hline
\end{tabular}

Nota: Esquema tomado de NICE 2020 (NG188).

Para lo cual se solicitó la participación a una encuesta de los padres de familia de niños, niñas y adolescente, la población hace referencia a 2200 estudiantes de dos colegios de la ciudad, que al realizar su caracterización y clasificación sobre las necesidades de la investigación se encuentra que son sujetos de estudio 80 menores de edad que se han infectado con el virus, entre edades de 5 a 17 años, de los cuales solo (12) doce de ellos manifestaron presentar una prolongación de signos o síntomas asociados al COVID-19 que continúan durante más de 12 semanas y son no explicado por un diagnóstico alternativo. 


\section{RESULTADOS}

\section{Manifestaciones Físicas y Cognitivas Más Comunes del Síndrome Post Covid-19}

En los estudios sobre la afectación del COVID-19 en la salud de los niños y niñas podemos encontrar que, aunque esta etapa del desarrollo exhibe un bajo riesgo de presentar un nivel agudo de la enfermedad, es relevante encontrar casos en los cuales se presenten cuadros inflamatorios tardíos los cuales pueden ocurrir en menos del $1 \%$ de los pacientes pediátricos. Este es denominado como síndrome inflamatorio multisistémico pediátrico vinculado a SARS-CoV-2 (SIM-PedS o MIS-C) y tiene similitud con enfermedades como la de Kawasaki (Bouza,2021). De igual forma es inevitable pensar en los efectos del COVID-19 prolongado en esta población, a pesar de que los estudios apuntan que se manifiesta en adultos afectando los sistemas neurológico, cardiorrespiratorio y sensorial, de igual forma la salud mental (Zimmermann et al., 2021).

Es así como un estudio de los efectos del síndrome en 312 pacientes al indagar en la población infantil en un rango de edad de 0 a 15 años encuentra que solo el 13\% señala haber presentado signos o síntomas prolongados, sin embargo, la población de 16 a 30 años tiene un gran aumento siendo un 52\% exhibieron persistencia en los síntomas, de igual manera se plantea que los síntomas prolongados pueden llegar a ocasionar problemas en el aprendizaje y proceso estudiantil (Blomberg et al., 2021). Por otro lado, la investigación llevada a cabo en 129 menores de 18 años sugiere que el 42,6\% manifestó haber presentado al menos un síntoma después de los 60 días después del contagio por el virus (Buonsenso et al., 2021). En otro estudio de seguimiento a 5 niños con edad promedio de 12 años estos al realizar la indagación sobre el síndrome post COVID-19 expresaron haber tenido síntomas como fatiga, disnea, palpitaciones del corazón 0 dolor en el pecho, y cuatro tenían dolores de cabeza, dificultad para concentrarse, debilidad muscular, mareos y dolor de garganta (Ludvigsson, 2021).

Según el informe de la Oficina de Estadísticas Nacionales del Reino Unido considera que el 12,9 \% de los menores de 2 a 11 años, y el 14,5 por ciento de los niños de 12 a 16 años, todavía manifiestan signos 0 síntomas cinco semanas después del primer contagio con el virus (Thomson, 2021). Por otra parte, un estudio de 72 niños de los cuales se centró la investigación en 8 pacientes confirmados con el síndrome, estos presentaron síntomas comunes persistentes como fiebre baja persistente, astenia y cefalea intensas (Nogueira et al., 2021). Asimismo, una investigación en 1734 niños en un rango de edad de 5 a 17 años positivos en la prueba SARS-CoV-2, el 4.4.\% presentaron una prolongación de la enfermedad durante más de 28 días, siendo los síntomas más comunes fueron fatiga, dolor de cabeza y anosmia (Molteni et al., 2021).

\section{Manifestaciones Psicológicas y Psiquiátricas más Comunes del Síndrome Post Covid-19}

La salud mental de las personas es un punto que debe ser atendido con sigilo más aun cuando los pacientes que han presentado síntomas agudos y posagudos del virus, en conjunto con las medidas de confinamiento y distanciamiento social presentan la aparición de trastornos de depresión, ansiedad y cambios de humor. Las secuelas en la salud mental y conductual en los niños, niñas y adolescentes es un aspecto para tenerse en cuenta por los profesionales de la salud cuando se realice un diagnóstico y tratamiento de nuevos síntomas respecto a pacientes que han superado el COVID-19, en cuanto a que la infección del virus SARS-CoV-2 puede llegar a producir secuelas en la salud mental que son relativamente comunes y probablemente multifactoriales (American Academy of Pediatrics, 2021). 
En cuanto a las manifestaciones prolongadas sobre la salud mental en los adolescentes se pueden encontrar estudios como el de Blomberg et al. (2021) que estudia la prevalencia del síndrome post COVID-19 en estudiantes universitarios, hallando que el $51 \%$ de los participantes que se recuperaron de la enfermedad se diagnosticaron en un cuadro de esta afección. Así mismo, un estudio con 1560 adolescentes de diferentes escuelas se llega a la conclusión que más de un tercio manifestó haber tenido dificultades psicológicas en cuanto a algún síntoma neurocognitivo, doloroso o anímico con tensión, apatía y dificultad para concentrarse (Blankenburg et al., 2021). Por otro lado, la investigación en 3065 adolescentes de 11 a 17 años plantea que un gran porcentaje de los participantes presentaron el síndrome además que los síntomas de salud física como mental están relacionados (Behnood et al., 2022). También podemos encontrar un estudio de 4678 niños que halló que el 10\% de los participantes diagnosticados con COVID-19 prolongado manifestaron síntomas psicológicos y psiquiátricos persistentes no especificados (Miller et al., 2021).

\section{Tabla 2}

Investigaciones sobre el síndrome post COVID-19.

\begin{tabular}{|c|c|c|c|c|c|c|c|}
\hline Autor & Lugar & Muestra & Instrumento & Tipo de estudio & $\begin{array}{c}\text { Rango de } \\
\text { edad }\end{array}$ & $\begin{array}{l}\text { Tiempo } \\
\text { duración }\end{array}$ & Síntomas Comunes \\
\hline $\begin{array}{l}\text { Blomberg et } \\
\text { al., (2021) }\end{array}$ & Noruega & 312 & $\begin{array}{l}\text { Entrevista } \\
\text { Clínica }\end{array}$ & $\begin{array}{l}\text { estudio de } \\
\text { cohorte } \\
\text { prospectivo }\end{array}$ & 16-30 años & $\begin{array}{l}\text { Después } \\
\text { de } 6 \\
\text { meses }\end{array}$ & $\begin{array}{l}\text { la pérdida del gusto y / o el olfato } \\
(28 \%, 17 / 61) \text {, fatiga }(21 \%, 13 / 61) \text {, } \\
\text { disnea }(13 \%, 8 / 61) \text {, alteración de la } \\
\text { concentración }(13 \%, 8 / 61) \text { y } \\
\text { problemas de memoria }(11 \%, 7 / 61) \text {. }\end{array}$ \\
\hline $\begin{array}{l}\text { Buonsenso et } \\
\text { al., (2021) }\end{array}$ & Italia & 129 & $\begin{array}{l}\text { Teléfono } \\
\text { entrevista } \\
\text { clínica }\end{array}$ & $\begin{array}{l}\text { estudio } \\
\text { transversal }\end{array}$ & $\begin{array}{l}\text { Menores de } \\
18 \text { años }\end{array}$ & $\begin{array}{l}\text { Después } \\
\text { de } 6 \\
\text { meses }\end{array}$ & $\begin{array}{l}\text { Insomnio }(18,6 \%) \text {, síntomas } \\
\text { respiratorios (que incluyen dolor y } \\
\text { opresión en el pecho) (14,7\%), } \\
\text { congestión nasal (12,4\%), fatiga } \\
(10,8 \%) \text {, dolores musculares }(10,1 \%) \\
\text { y articulares }(6,9 \%) \text { y dificultades de } \\
\text { concentración }(10,1 \%)\end{array}$ \\
\hline $\begin{array}{l}\text { Ludvigsson, } \\
\text { (2021) }\end{array}$ & Suecia & 5 & $\begin{array}{l}\text { Entrevista } \\
\text { Clínica }\end{array}$ & $\begin{array}{l}\text { estudio } \\
\text { transversal }\end{array}$ & $9-15$ & $6-8$ meses & $\begin{array}{l}\text { Fatiga, disnea, palpitaciones del } \\
\text { corazón o dolor en el pecho, y cuatro } \\
\text { tenían dolores de cabeza, dificultad } \\
\text { para concentrarse, debilidad muscular, } \\
\text { mareos y dolor de garganta. }\end{array}$ \\
\hline $\begin{array}{l}\text { Thomson H. } \\
\text { (2021). }\end{array}$ & $\begin{array}{l}\text { Reino } \\
\text { Unido }\end{array}$ & 1200 & $\begin{array}{l}\text { Entrevista } \\
\text { Clínica }\end{array}$ & $\begin{array}{l}\text { estudio } \\
\text { transversal }\end{array}$ & $2-16$ & $\begin{array}{l}5-8 \\
\text { semanas }\end{array}$ & $\begin{array}{l}\text { Fatiga, dolor muscular y articular, dolor } \\
\text { de cabeza, insomnio, problemas } \\
\text { respiratorios y palpitaciones cardíacas. }\end{array}$ \\
\hline $\begin{array}{l}\text { Nogueira, et al. } \\
\text { (2021) }\end{array}$ & España & 72 & Telefónica & $\begin{array}{l}\text { estudio de } \\
\text { cohorte } \\
\text { prospectivo }\end{array}$ & $\begin{array}{l}\text { Menores de } \\
18 \text { años }\end{array}$ & 6-8 meses & $\begin{array}{l}\text { Fiebre baja persistente, astenia intensa } \\
\text { y cefalea intensa. }\end{array}$ \\
\hline $\begin{array}{l}\text { Blankenburg et } \\
\text { al. (2021) }\end{array}$ & Alemania & 1560 & Encuesta & $\begin{array}{l}\text { estudio } \\
\text { exploratorio }\end{array}$ & $\begin{array}{l}\text { Edad } \\
\text { promedio } 15 \\
\text { años }\end{array}$ & $6-8$ meses & $\begin{array}{l}\text { Síntoma neurocognitivo, doloroso } 0 \\
\text { anímico con tensión, apatía y dificultad } \\
\text { para concentrarse. }\end{array}$ \\
\hline $\begin{array}{l}\text { Stephenson et } \\
\text { al. (2021) }\end{array}$ & $\begin{array}{l}\text { Reino } \\
\text { Unido }\end{array}$ & 3065 & Cuestionario & $\begin{array}{l}\text { estudio } \\
\text { transversal }\end{array}$ & 11-17 años & $\begin{array}{l}3 \text { meses } \\
\text { después }\end{array}$ & $\begin{array}{l}\text { Fatiga, dolor muscular y articular, dolor } \\
\text { de cabeza, insomnio. }\end{array}$ \\
\hline $\begin{array}{l}\text { Miller et al. } \\
(2021)\end{array}$ & $\begin{array}{l}\text { Reino } \\
\text { Unido }\end{array}$ & 4678 & Cuestionario & $\begin{array}{l}\text { estudio } \\
\text { transversal }\end{array}$ & 12-17 años & 6-8 meses & $\begin{array}{l}\text { Síntomas generales, } \\
\text { otorrinolaringológicos y respiratorios }\end{array}$ \\
\hline $\begin{array}{l}\text { Molteni et } \\
\text { al.(2021) }\end{array}$ & $\begin{array}{l}\text { Reino } \\
\text { Unido }\end{array}$ & 1734 & Cuestionario & $\begin{array}{l}\text { estudio } \\
\text { transversal }\end{array}$ & 5 a 17 años & $\begin{array}{l}\text { Mas de } 28 \\
\text { días }\end{array}$ & Fatiga, dolor de cabeza y anosmia \\
\hline $\begin{array}{l}\text { Rusetsky et al. } \\
\text { (2021) }\end{array}$ & Rusia & 79 & $\begin{array}{l}\text { Encuesta } \\
\text { telefónica }\end{array}$ & $\begin{array}{l}\text { Estudio clínico } \\
\text { prospective } \\
\text { transversal }\end{array}$ & 12-17 años & $\begin{array}{l}60 \text { días } \\
\text { después }\end{array}$ & Problemas estado olfativo \\
\hline $\begin{array}{l}\text { Zavala et al. } \\
(2021)\end{array}$ & $\begin{array}{l}\text { Reino } \\
\text { Unido }\end{array}$ & 472 & $\begin{array}{l}\text { Encuesta } \\
\text { telefónica }\end{array}$ & $\begin{array}{l}\text { estudio } \\
\text { transversal }\end{array}$ & 2 a 16 años & $\begin{array}{l}30 \text { días } \\
\text { después }\end{array}$ & $\begin{array}{l}\text { Los síntomas agudos más prevalentes } \\
\text { fueron tos }(249 / 859,29,0 \%) \text {, fiebre } \\
(236 / 859,27,5 \%) \text {, dolor de cabeza }\end{array}$ \\
\hline
\end{tabular}


$(236 / 859,27,4 \%)$ y fatiga $(231 / 859$, $26,9 \%)$.

Nota: En la tabla se puede apreciar la discriminación de algunos de los estudios relevantes sobre el síndrome post COVID-19 en los niños, niñas y adolescentes. Creación propia.

\section{Resultados de la Encuesta}

Para el análisis de los resultados se utilizó la estadística descriptiva para medir cada una de las variables del estudio, utilizando un programaba básico somo Excel, que permite organizar, manejar, realizar operaciones de manera sencilla y práctica.

\section{Figura 1}

\section{Signos y síntomas manifestados por los participantes de la encuesta.}

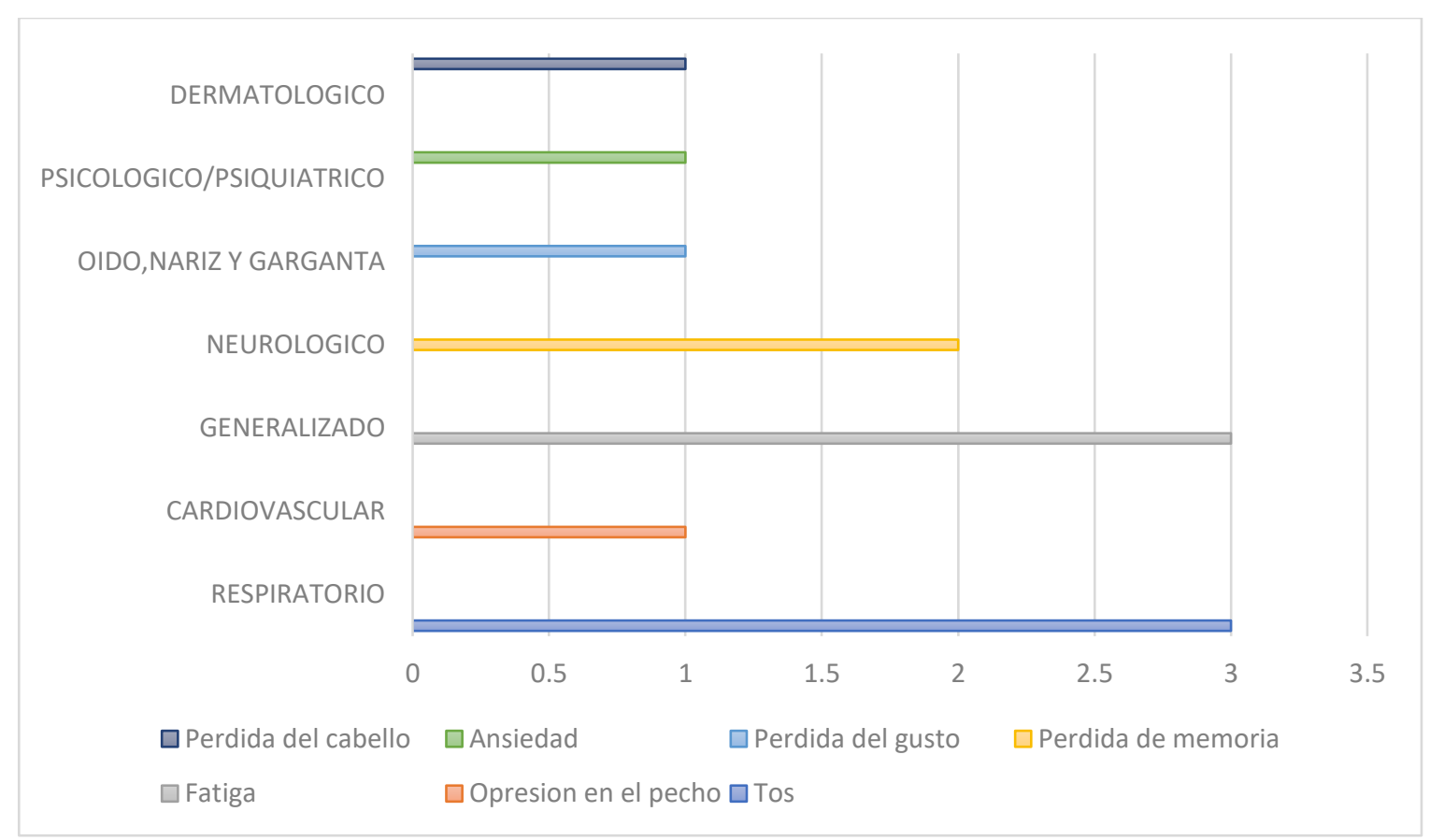

Nota: En la figura se observan los síntomas prolongados del COVID-19 comunes presentados por la muestra en estudio.

Por lo tanto el 25\% del total de la muestra en estudio manifestaron haber presentado síntomas respiratorios prolongados como tos, el 25\% informaron padecer de signos generalizados como fatiga, el 16,67\% expusieron padecimientos neurológicos como pérdida de memoria, por otro lado un 8,33\% dieron a conocer afecciones dermatológicas como caída del cabello, así como el 8,33\% problemas de oído, nariz y garganta con una pérdida del gusto, también 8,33\% afección cardiovascular opresión en el pecho y 8,33\% con síntomas psicológicos 0 psiquiátricos en relación al trastorno de ansiedad. 


\section{Figura 2}

\section{Etapas del desarrollo en estudio}

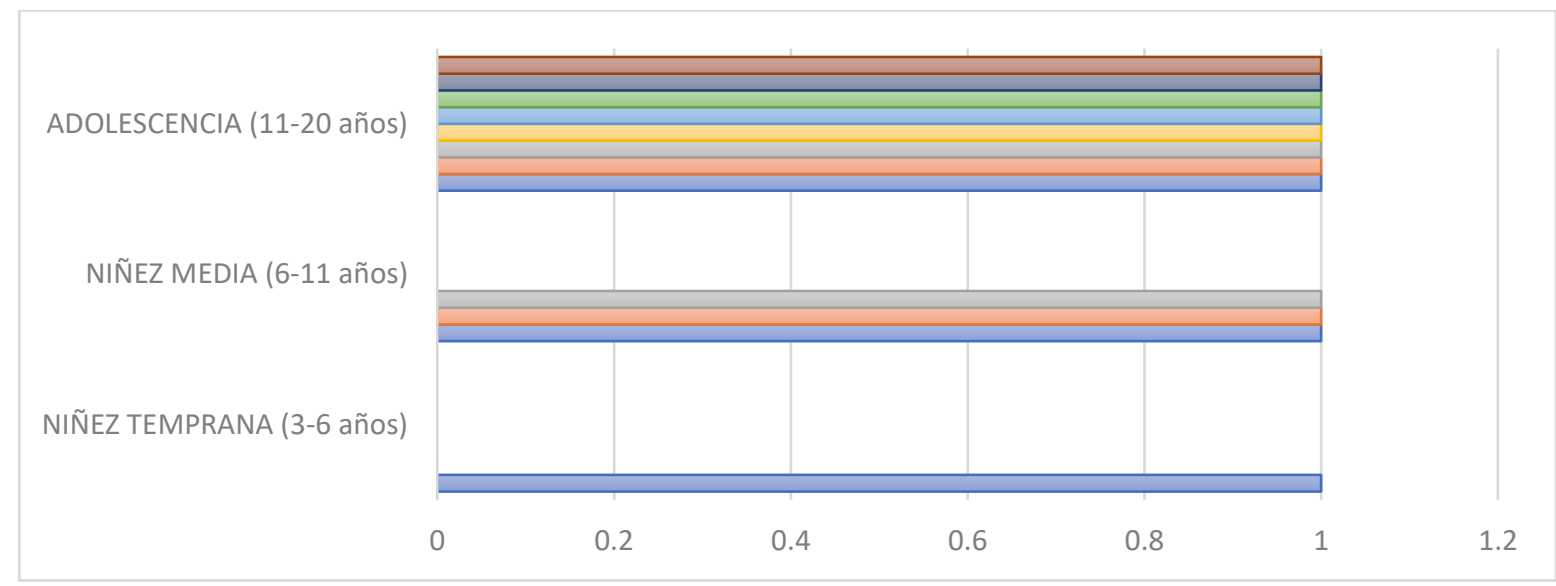

Nota: La figura se observa la discriminación de los datos por etapas del desarrollo humano.

Por otro lado, al realiza la comparación por edades tenemos que un 8,33\% en la niñez temprana, el 25\% están en la niñez media (6-11 años) y el 66,67\% de los participantes adolescentes que comprende la etapa entre las edades de 11 a 20 años siendo una etapa de transición que presenta cambios representativos significativos en aspectos físicos, cognitivos y psicosociales (Papalia et al., 2017).

\section{CONCLUSIONES}

Las investigaciones sobre el tema apuntan a que la enfermedad del síndrome post COVID-19 en niños y niñas tiene un bajo riesgo, pero en adolescentes y adultos jóvenes se incrementa la posibilidad de padecer la prolongación de signos y síntomas del virus, esto lo confirma el análisis de los datos recolectados por la encuesta donde esta etapa del desarrollo se concentran los efectos del síndrome en un gran porcentaje. Por esta razón, es indispensable la vacunación para prevenir las afecciones agresivas del COVID-19 pero también es un recurso para la prevención de los síntomas prolongados con efectos agresivos potenciales sobre la salud a largo plazo en los menores y adultos.

La niñez es una etapa del desarrollo fundamental para la vida de una persona, en donde se adquiere las habilidades, destrezas y aprendizajes para el desempeño a nivel físico, psicológico, social, cultural, conductual y educativo, de igual forma la niñez tiene una especial protección por parte de la sociedad. Por consiguiente, el síndrome post COVID-19 al afectar a largo plazo cualquiera de sus componentes esenciales, conlleva una gran importancia en su investigación, diagnóstico y tratamiento, por lo tanto, los profesionales en salud, como pediatras, psiquiatras, psicólogos, terapeutas, etc., al igual que los gobiernos de turnos deben trabajar en consenso para la construcción de procesos y políticas para reducir el impacto de la pandemia del COVID-19 en los niños, niñas y adolescentes.

Además, el síndrome post COVID-19 se compone de afecciones que se postulan como un problema de salud general que adquiere cada día una gran relevancia y debida respuesta global por parte de todas las instituciones de la sociedad, en las etapas de investigación, gestión sanitaria e información. De igual forma se debe apoyar 
mayores estudios prospectivos, más allá de encuestas y llevarlos a la evaluación clínica objetiva, como manera de comprender las implicaciones en la salud del COVID prolongado desde las primeras etapas del crecimiento.

\section{Conflicto de intereses / Competing interests:}

El autor declara que no incurre en conflictos de intereses.

Rol de los autores / Authors Roles:

No aplica

\section{Fuentes de financiamiento / Funding:}

El autor declara que no recibió un fondo específico para esta investigación.

\section{Aspectos éticos / legales; Ethics / legals:}

El autor declara no haber incurrido en aspectos antiéticos, ni haber omitido aspectos legales en la realización de la investigación.

\section{REFERENCIAS}

American Academy of Pediatrics. (2021). Post-COVID-19 conditions in children and adolescents. https://bit.ly/345qo6D

Arias, F. (2006). El Proyecto de Investigación. introducción a la metodología científica (5ª). Episteme.

Behnood, S., Shafran, R., Bennett, S., Zhang, A., O'Mahoney, L., Stephenson, T., Ladhani, S., De Stavola, B., Viner, R., \& Swann, 0. (2022). Persistent symptoms following SARS-CoV-2 infection amongst children and young people: A meta-analysis of controlled and uncontrolled studies. Journal of Infection, 84(2), 158-170. https://doi.org/10.1016/j.jinf.2021.11.011

Blankenburg, J., Wekenborg, M., Reichert, J., Kirsten, C., Kahre, E., Haag, L., Schumm, L., Czyborra, P., Berner, R., \& Armann, J. (2021). Mental health of adolescents in the pandemic: Iong-COVID-19 or long-pandemic syndrome? SSRN Electronic Journal. https://doi.org/10.2139/ssrn.3844826

Blomberg, B., Mohn, K., Brokstad, K., Zhou, F., Linchausen, D. W., Hansen, B., Lartey, S., Onyango, T. B., Kuwelker, K., Sævik, M., Bartsch, H., Tøndel, C., Kittang, B., Madsen, A., Bredholt, G., Vahokoski, J., Fjelltveit, E., Bansal, A., Trieu, M. C., ... Langeland, N. (2021). Long COVID in a prospective cohort of home-isolated patients. Nature Medicine, 27(9), 1607-1613. https://doi.org/10.1038/s41591-021-014333

Buonsenso, D., Munblit, D., De Rose, C., Sinatti, D., Ricchiuto, A., Carfi, A., \& Valentini, P. (2021). Preliminary evidence on long COVID in children. Acta Paediatrica, 110(7), 2208-2211. https://doi.org/10.1111/apa.15870

Giraldo, C., Tamayo, C., López, E., Caicedo, M., \& Piñeres, B. (2020). Síndrome inflamatorio multisistémico en niños asociado a COVID-19. Revisión narrativa de la literatura a propósito de un caso. Acta Colombiana de Cuidado Intensivo. https://doi.org/10.1016/j.acci.2020.11.002

Hernández, R., Fernández, C., \& Baptista, P. (2014). Metodología de la investigación. Mc Graw Hill.

Instituto Nacional para la Excelencia en la Salud y la Atención. (2020). COVID-19 rapid guideline: managing the longterm effects of COVID-19. https://bit.ly/3CaMH7x

Ludvigsson, J. (2021). Case report and systematic review suggest that children may experience similar longterm effects to adults after clinical COVID-19. Acta Paediatrica, 110(3), 914-921. https://doi.org/10.1111/apa.15673

Miller, F., Nguyen, V., Navaratnam, A., Shrotri, M., Kovar, J., Hayward, A., \& Fragaszy, E. (2021). Prevalence of persistent symptoms in children during the COVID-19 pandemic: evidence from a household cohort study 
in England and Wales. MEdRxiv. https://doi.org/10.1101/2021.05.28.21257602

Molteni, E., Sudre, C., Canas, L., Bhopal, S., Hughes, R., Antonelli, M., Murray, B., Kläser, K., Kerfoot, E., Chen, L., Deng, J., Hu, C., Selvachandran, S., Read, K., Capdevila, J., Hammers, A., Spector, T., Ourselin, S., Steves, C., ... Duncan, E. (2021). Illness duration and symptom profile in symptomatic UK school-aged children tested for SARS-CoV-2. The Lancet Child \& Adolescent Health, 5(10), 708-718. https://doi.org/10.1016/S2352-4642(21)00198-X

Nogueira, J., Grasa, C., Calvo, C., \& García, M. (2021). Long-term symptoms of COVID-19 in children. Acta Paediatrica, 110(7), 2282-2283. https://doi.org/10.1111/apa.15849

Organización Mundial de la Salud. (2020). Síndrome inflamatorio multisistémico en niños y adolescentes con COVID-19. https://bit.ly/3IRTOQd

Papalia, D., Wendkos, S., \& Duskin, R. (2017). Desarrollo Humano (Undecima e). Mc Graw Hill.

Thomson, H. (2021). Children with long covid. New Scientist, 249(3323), 10-11. https://doi.org/10.1016/S0262-4079(21)00303-1

Zimmermann, P., Pittet, L., \& Curtis, N. (2021). How common is long COVID in children and adolescents? Pediatric Infectious Disease Journal, 40(12), e482-e487. https://doi.org/10.1097/INF.0000000000003328 